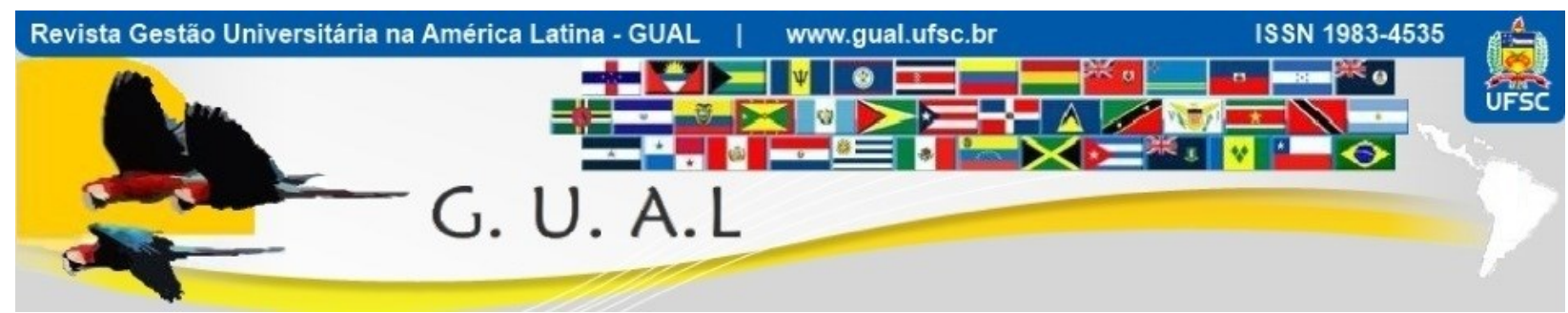

DOI: http://dx.doi.org/10.5007/1983-4535.2017v10n3p97

\title{
EVOLUÇÃO DA EDUCAÇÃO SUPERIOR A DISTÂNCIA NO BRASIL: UMA ANÁLISE A PARTIR DE PROCESSOS DE INSTITUCIONALIZAÇÃO
}

THE EVOLUTION OF DISTANCE EDUCATION IN BRAZIL: AN ANALYSIS FROM ITS INSTITUTIONALIZATION PROCESSES

Jorge da Silva Correia-Neto, Doutor Universidade Federal Rural de Pernambuco - UFRPE jorgecorreianeto@gmail.com

José de Arimatéia Dias Valadão, Doutor

Universidade Federal de Lavras - UFLA jose.valadao@dae.ufla.br

Recebido em 20/julho/2015

Aprovado em 24/maio/2017

Sistema de Avaliação: Double Blind Review

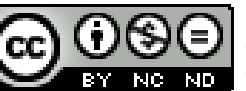

Esta obra está sob uma Licença Creative Commons Atribuição-Uso. 


\title{
RESUMO
}

A educação a distância no Brasil passa a ganhar destaque a partir dos anos 2000, com a Universidade Aberta do Brasil e com a inserção dessa modalidade no Plano Nacional de Educação 2001-2010, que tinha como meta a provisão do ensino superior a $30 \%$ da população entre 18 e 24 anos. Visando refletir sobre essa realidade, o estudo discorreu sobre a evolução da educação a distância no Brasil, sob a ótica da teoria institucional, a partir do seguinte questionamento: como tem se dado o processo de institucionalização da $\mathrm{EaD}$ no Brasil? Para dar conta desse objetivo, a pesquisa foi realizada em duas etapas: a primeira envolveu o registro da história da $\mathrm{EaD}$ e a segunda a identificação dos principais indícios de sua institucionalização. Os procedimentos metodológicos envolveram análise documental e de conteúdo, realizadas em dois cortes temporais. De modo geral, o processo de institucionalização da educação a distância no Brasil se mostrou como dinâmico e permanente, e a teoria institucional mostrou-se relevante para descrever as transformações que ocorrem em áreas estratégicas, como é o caso da EaD. Foram ainda apontadas sugestões de estudos futuros.

Palavras chave: Educação a distância. Teoria institucional. Institucionalização.

\begin{abstract}
Distance education in Brazil gains prominence from the 2000s, with the Open University of Brazil and with its insertion on the National Educational Plan 2001-2010, that intended to provide the superior education to $30 \%$ of the Brazilian population from 18 to 24 years old. Aiming to reflect over this reality, the study discussed the evolution of distance education in Brazil, using the institutional theory lenses, questioning how this process of institutionalization has been going on through the last decades. To answer this questioning, this manuscript was developed in two steps: the first one presents the history of distance education in Brazil and the second one shows its main signs of institutionalization. The methodological procedures involved the content analysis of two deep interviews and an extensive document analysis. As results, this manuscript points out that the process of institutionalization of distance education in Brazil is dynamic and permanent, and that institutional theory lenses are relevant to describe transformations that occurs in strategic areas such as distance education. The study also presents future work.
\end{abstract}

Keywords: Distance education. Institutional theory. Institutionalization. 


\section{INTRODUÇÃO}

A educação a distância (EaD) no Brasil, especialmente no nível de graduação, vem se consolidando nos últimos anos. No ensino superior as experiências de EaD começaram nos anos de 1990, mas começaram a se consolidar a partir do ano 2000 com a Universidade Aberta (UAB), que vem capitaneando as ações governamentais nessa área. Tal fato é atestado por suas bases legais estabelecidas pela Lei de Diretrizes e Bases da Educação Nacional (LEI n. ${ }^{\circ}$ 9.394/96), cujo artigo 80 inseriu a modalidade de EaD no País, o que evidencia a importância dessa modalidade no contexto da educação nacional (MEC, 2010) e por sua inclusão nos Planos Nacionais de Educação (RODRIGUES et al., 2014).

Essa importância é reforçada pelo número de alunos na modalidade $\mathrm{EaD}$ em instituições de ensino superior (IES), "que hoje já ultrapassa o número de alunos presenciais", como afirmou Celso José da Costa, diretor de Educação a Distância do Ministério da Educação, durante a constituição do Fórum da Área de Administração Pública do Sistema UAB, que reuniu dezenas de coordenadores de curso de graduação e especialização de IES brasileiras, em dezembro de 2010. O ProUni também contribui para esse crescimento, pois viabiliza o acesso de jovens carentes à rede particular de ensino superior, com bolsas também para a modalidade EaD (SEGENREICH, 2010), reforçando o caráter inclusivo da EaD (FERRUGINI, 2013).

Contudo, ainda existem poucas pesquisas sobre o processo de institucionalização dessas experiências ao longo do Brasil. Assim, partindo do pressuposto que a Teoria Institucional é um campo teórico dentro dos estudos organizacionais relevante para tratar dessa problemática, advieram os seguintes questionamentos: como tem se dado a evolução da $\mathrm{EaD}$ no Brasil, a partir de processos de institucionalização, da EaD no Brasil? Já é possível falar em sedimentação da EaD no Brasil?

Para discutir essas questões, o estudo está subdivido em mais quatro seções. A próxima apresenta o referencial teórico, discutindo sobre a EaD no Brasil e teorias e processos de institucionalização. São apresentados também os procedimentos metodológicos, os resultados e discussões do estudo e suas considerações finais.

\section{EDUCAÇÃO A DISTÂNCIA NO BRASIL}

As primeiras experiências educativas a distância desenvolveram-se com êxito ainda nos séculos XVII e XIX, mas é a partir do final do séc. XX, com a introdução de elementos 
tecnológicos como TV, vídeo e Internet que elas passam a tomar corpo (NUNES, 1994; SOUZA; FERRUGINI; CASTRO, 2014). Nessa versão moderna, a Open University da Inglaterra pode ser considerada uma das pioneiras na oferta de cursos a distância, em especial por conta da implementação do conceito de polos de apoio presencial, já em 1969 (OPEN UNIVERSITY, 2007). Duas outras experiências devem ser destacadas: a dos e-centers na China, que respondem por grande parte de uma rede de educação a distância na área rural, e a da Universidade Aberta de Portugal, com centros de apoio distribuídos por todo o país (MORAES, 2010).

No Brasil, na década de 1980, o Ministério da Educação (MEC) propôs o projeto EDUCOM (1983) e o Programa Nacional de Informática na Educação (PRONINFO) (1989), ambos destinados à introdução da informática na educação. Na década de 1990, o MEC ratifica esse direcionamento criando o Programa TV Escola (MEC, 2010).

No ensino superior brasileiro, as experiências de EaD começaram nos anos 1990, com o Consórcio Interuniversitário de Educação Continuada e a Distância (BRASILEAD) e com a UNIREDE. Vale ressaltar ainda o projeto Universidade Aberta (UAB), que vem capitaneando as ações governamentais nessa área desde 2005. Do ponto de vista legal, a EaD passa a fazer parte do sistema educacional formal brasileiro a partir da Lei n. 9.394/96, que estabeleceu as Diretrizes e Bases da Educação Nacional - LDBEN/96 e lá incluiu esta modalidade.

Na LDBEN/96 foi criada a possibilidade de oferta dessa modalidade de ensino, ficando suas normas de credenciamento, supervisão e avaliação para dezembro de 2005, quando houve a aprovação da Regulamentação Geral da EAD (DEC 5.622/2005, p. 1). Também fica explicitado como educação a distância a "modalidade educacional na qual a mediação didático-pedagógica nos processos de ensino e aprendizagem ocorre com a utilização de meios e tecnologias de informação e comunicação, com estudantes e professores desenvolvendo atividades educativas em lugares ou tempos diversos". Vale destacar ainda que esse intervalo regulatório não impediu que esta modalidade se expandisse rapidamente, passando de 7 para 115 IES oferecendo cursos de graduação a distância entre 2000 e 2008, totalizando nesse ano cerca de 700 mil matrículas (SEGENREICH, 2010).

Para Moran (1994), a EaD é vista como suporte ao processo de ensino-aprendizagem que tem por característica a separação física entre professores e alunos, mas que podem estar conectados, interligados por algum tipo de tecnologia que possibilita a interação entre eles, principalmente as telemáticas. Essa interação é um dos elementos instrucionais mais críticos 
da EaD (WILLIS, 1994; NEVADO, 1996). Moore (1973, p. 661) complementa afirmando que:

EaD é uma família de métodos instrucionais nos quais comportamentos de ensino são executados em separado dos comportamentos de aprendizagem, incluindo aqueles que numa situação presencial seriam desempenhados na presença do aluno, de modo que a comunicação entre o professor e o aluno deve ser facilitada por dispositivos impressos, eletrônicos, mecânicos e outros.

Nesse contexto surgiram os ambientes virtuais de aprendizagem (AVA), que são os sistemas de informação utilizados por alunos e professores para interagir e construir os conhecimentos formais objetivados. Neles também existem funcionalidades para acompanhamento das notas das atividades virtuais e presenciais.

\section{PROCESSOS DE INSTITUCIONALIZAÇÃO}

Até meados do século $\mathrm{XX}$ as organizações não eram tidas como objeto de estudo da Sociologia. É a partir dos estudos de Robert Merton nos anos 1940 que as organizações começaram a serem vistas como fenômeno social distinto, mesmo levando-se em conta os profícuos trabalhos de Weber e da Escola de Chicago. Nessa época o foco estava na dinâmica da mudança social, no exame da co-variação entre diferentes elementos da estrutura e na análise do equilíbrio dinâmico entre os efeitos benéficos e disfuncionais de determinados arranjos estruturais. Essa análise tinha duas premissas: "os componentes estruturais de um sistema devem ser integrados para que um sistema sobreviva" (TOLBERT; ZUCKER, 2007, p. 196), uma vez que os componentes são partes inter-relacionadas do todo e; "as estruturas existentes contribuem para o funcionamento de um sistema social" (TOLBERT; ZUCKER, 2007, p. 196, p.196), pelo menos para a manutenção de seu equilíbrio, pois, de outro modo, o sistema não sobreviveria (TOLBERT; ZUCKER, 2007).

Um dos autores seminais da teoria institucional é Philip Selznick. Selznick (1966, p. 251), em seu texto originalmente publicado em 1949, estudou como a Tennessee Valley Authority (TVA), autarquia federal norte-americana responsável pela implementação de um projeto de desenvolvimento numa região pobre no começo do séc. XX podia realmente "ser vista como uma estrutura social adaptativa”, inclusive negociando a participação de atores externos a organização nos seus conselhos diretivos. Com esse estudo, a evolução e sobrevivência das organizações em seu contexto institucional deixaram de ser vistas apenas 
como um instrumento que ajusta racionalmente os meios aos fins, mas também como uma “instituição" que tem valor próprio e que interage não só com o ambiente-técnico, mas também com o ambiente institucional. Surgiam, ali, as raízes da teoria institucional.

Para Selznick (1966), a institucionalização é um processo que reflete a própria história da organização e explica a forma pela qual a organização e os indivíduos criam significados, interpretando os fenômenos, ocupando posições de poder e se relacionando. A longevidade dessas organizações não é simplesmente um mero exercício de sobrevivência, mas sim uma luta para preservar valores únicos dela, pois, ao criar um conjunto distintivo de valores, as organizações se convertem em estruturas com caráter e adquirem uma identidade.

Refletindo sobre esta obra de Selznick, Fachin e Mendonça (2003, p. 36, inserção nossa), afirmam que "Selznick constata uma fraqueza da burocracia em confronto com forças do ambiente, admitindo-se mudanças que não teriam ocorrido caso a política original tivesse sido seguida", e complementam dizendo que "os valores ambientais podem condicionar sua [dos indivíduos] ação racional".

$\mathrm{Na}$ década de 1960, os estudos sociológicos acrescentaram a influência do ambiente externo na análise sociológica das organizações, e os anos de 1970 são marcados pelo surgimento de novos paradigmas explicativos. Um desses paradigmas é o das propriedades das estruturas. Segundo Meyer e Rowan (1977), as estruturas formais têm tanto propriedades simbólicas como capacidade de gerar ação. Nessa visão, a estrutura formal pode ser utilizada também para propósitos simbólicos, particularmente no sentido de ressaltar as limitações de explicações de cunho mais racional da estrutura.

Baseado nessa noção de que uma estrutura formal pode indicar um comprometimento com padrões de eficiência e racionalidade da organização, Tolbert e Zucker (2007) apontam três principais implicações. A primeira é que a adoção da estrutura formal pode ocorrer independentemente da existência de problemas específicos e imediatos de coordenação e controle relativos às atividades de seus membros. A segunda é que a avaliação social das organizações e, consequentemente, de sua sobrevivência, pode estar na observação das estruturas formais (que podem ou não funcionar de fato), em vez de estar nos resultados observáveis relacionados ao desempenho das tarefas em questão. A terceira é que a relação entre atividades do dia a dia e os comportamentos dos membros da organização e das estruturas formais pode ser negligenciada. 
Como sintetizado na Figura 1, Tolbert e Zucker (2007) afirmam ainda que a institucionalização é um processo de tipificação recíproca de atos habitualizados (desenvolvidos empiricamente e adotados) por seus atores. Com o passar do tempo, esses atos vão se tornando generalizados e independentes de indivíduos específicos, generalizando seu significado e levando a sua objetificação. Outro elemento central da Teoria Institucional é a exterioridade ou sedimentação, que é o grau em que essas tipificações são vivenciadas como possuindo uma realidade própria e perpassadas para outros membros do grupo.

Num contexto organizacional, a habitualização envolve os ajustes estruturais e sua normalização em termos de políticas e procedimentos, numa ou num conjunto de organizações com problemas semelhantes. Estes processos resultam em estruturas que podem ser classificadas como um estágio de pré-institucionalização. A objetificação envolve o desenvolvimento de certo grau de consenso social entre os dirigentes a respeito do valor de sua estrutura, e a crescente adoção por outras organizações congêneres. Assim, a objetificação da estrutura é consequência do monitoramento que a organização faz dos competidores e de esforços para aumentar sua competitividade.

Figura 1 Processos inerentes à institucionalização

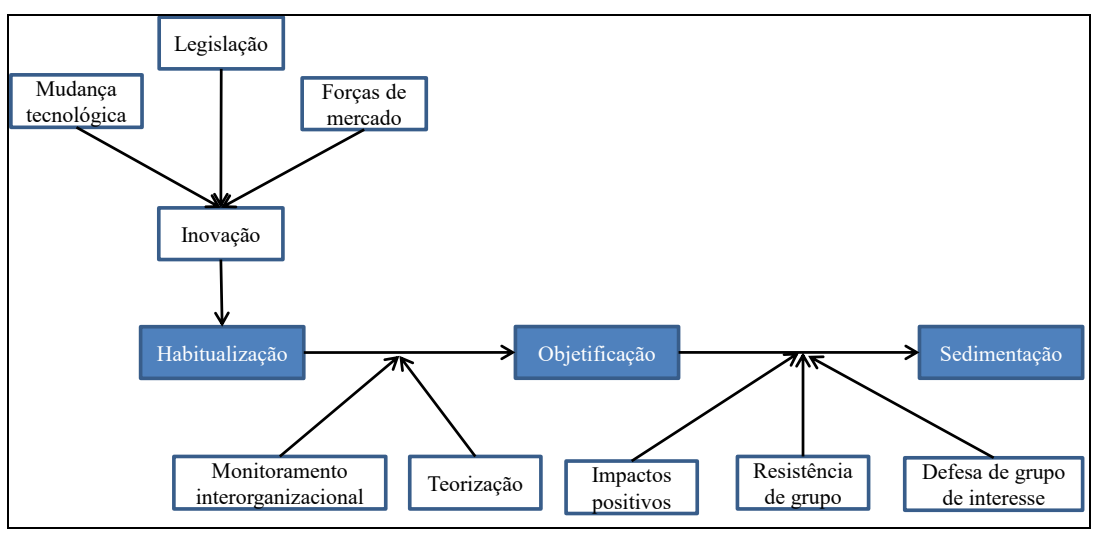

Fonte: Tolbert e Zucker (2007).

Em sua forma mais completa, a institucionalização se dá por meio da sedimentação, que se apoia na continuidade da estrutura e, especialmente, na sobrevivência das gerações dos membros da organização. A adoção dessas estruturas se dá pelo grupo de atores potenciais adotantes e pela perpetuação de estruturas por um período consideravelmente longo de tempo.

Assim, a teoria institucional considera os processos pelos quais as estruturas, incluindo esquemas, regras, normas e rotinas, se estabelecem como diretrizes autoritárias para o comportamento social. Investiga como esses elementos são criados, difundidos, adotados e 
adaptados ao longo do espaço e do tempo e a forma como elas caem em decadência e desuso (SCOTT, 2004). Sua principal ênfase é o reconhecimento da base social e cultural da influência externa sobre as organizações, e que essa influência se dá dialeticamente entre os diversos atores dessa teia interorganizacional que se forma com o tempo (HATCH; CUNLIFFE, 2006).

\section{PROCEDIMENTOS METODOLÓGICOS}

A pesquisa, de natureza qualitativa, foi realizada em dois cortes no tempo: durante o segundo semestre de 2012 e durante o segundo semestre de 2014. No primeiro corte a pesquisa transcorreu em duas etapas, a saber: identificar a história da $\mathrm{EAD}$, principalmente no Brasil e; identificar os principais indícios de sua institucionalização. Em ordem cronológica, na primeira etapa foi feita a análise da legislação sobre a $\mathrm{EaD}$ e das publicações que destacavam a trajetória da EaD no Brasil. Na segunda etapa foi realizada uma entrevista em profundidade com um coordenador de curso de graduação de EaD de uma Instituição Pública de Ensino Superior (IPES), aqui apresentado como "CoordEaD”, 2012 ou 2014 conforme o ano da entrevista, e foram analisados documentos da instituição relacionados às ações que estavam sendo desenvolvidas nessa IPES. No segundo corte, foi realizada uma nova entrevista em profundidade com o mesmo coordenador do primeiro corte.

O método de análise utilizado foi a análise de conteúdo, que segundo Bardin (2004) é um conjunto de técnicas de análise visando obter, qualitativa ou quantitativamente, indicadores que permitem obter conhecimentos relativos à produção documentais, objetivando extrair mensagens que permitam a geração de novos conhecimentos, no caso do presente artigo, a institucionalização da EaD no Brasil.

Quadro 1 Materiais selecionados para análise.

\begin{tabular}{|c|c|c|c|}
\hline Bases & Documentos & Aspectos analisados & Motivo da Escolha \\
\hline \multirow[b]{2}{*}{ Legislações } & $\begin{array}{l}\text { Lei 9.394/1996(LDB); } \\
\text { Decreto 5.622/2005; } \\
\text { Decreto 6.303/2007; } \\
\text { Portaria318/2009. }\end{array}$ & $\begin{array}{l}\text { Artigo } 80 \text { que trata da EAD; } \\
\text { Regulamenta a EaD na LDB; } \\
\text { Alterações no decreto } \\
5.622 / 2005 ; \\
\text { Trata da UAB na CAPES. }\end{array}$ & $\begin{array}{l}\text { Destacam a história da } \\
\text { EaD no Brasil e seu } \\
\text { processo } \\
\text { institucionalização. }\end{array}$ \\
\hline & $\begin{array}{l}\text { Lei 10.172/2001; } \\
\text { Portaria 4.059/2004; } \\
\text { Lei 11.096/2005; } \\
\text { Decreto 5.800/2006; } \\
\text { Portaria 9/2009. }\end{array}$ & $\begin{array}{l}\text { Trata do PNE; } \\
\text { Regulamenta sobre os } 20 \% \\
\text { EAD; } \\
\text { Sobre o PROUNI e a EaD; } \\
\text { Sobre a UAB; } \\
\text { Sobre a formação em EAD. }\end{array}$ & $\begin{array}{l}\text { Destacam a história da } \\
\text { EaD e aspectos que } \\
\text { indicam sua expansão } \\
\text { no Brasil }\end{array}$ \\
\hline
\end{tabular}




\begin{tabular}{|c|c|c|c|}
\hline & $\begin{array}{l}\text { Decreto 2.5622/2005; } \\
\text { Lei } 10.861 / 2004 ; \\
\text { Portarias } 1 / 2007 \quad \text { e } \\
10 / 2009 ;\end{array}$ & $\begin{array}{l}\text { Disposições sobre EaD; } \\
\text { Sobre o SINAES; } \\
\text { Sobre EaD e os polos nos } \\
\text { municípios. }\end{array}$ & $\begin{array}{l}\text { Destacam a história da } \\
\text { EaD e aspectos que } \\
\text { indicam suas } \\
\text { regulações no Brasil }\end{array}$ \\
\hline \multirow{3}{*}{ Publicações } & $\begin{array}{l}\text { Alves (2011); } \\
\text { Faria e Salvadori } \\
(2010) ;\end{array}$ & $\begin{array}{l}\text { História da } \mathrm{EaD} ; \\
\text { Análise sobre a EaD e história; }\end{array}$ & $\begin{array}{ll}\text { Detalhamento } & \text { da } \\
\text { história da EaD } & \text { no } \\
\text { Brasil e no mundo. } & \end{array}$ \\
\hline & $\begin{array}{l}\text { Neto (2012); } \\
\text { Lapa e Pretto (2010); }\end{array}$ & $\begin{array}{l}\text { Institucionalização; } \\
\text { Crítica à EaD; }\end{array}$ & $\begin{array}{l}\text { Analisam no Brasil } \\
\text { institucionalmente a } \\
\text { EaD }\end{array}$ \\
\hline & $\begin{array}{l}\text { Censo EaDBr. (2009); } \\
\text { Censo EaDBr. (2011); }\end{array}$ & Números sobre EaD no Brasil. & $\begin{array}{l}\text { É uma das bases mais } \\
\text { atualizadas sobre EaD }\end{array}$ \\
\hline Entrevistas & $\begin{array}{l}\text { Relatos no primeiro e } \\
\text { segundo corte }\end{array}$ & Informações relevantes. & $\begin{array}{l}\text { É uma das formas } \\
\text { mais contextualizadas } \\
\text { de obtenção de } \\
\text { informações confiáveis } \\
\text { e críticas. }\end{array}$ \\
\hline $\begin{array}{l}\text { Documentos } \\
\text { da IES }\end{array}$ & $\begin{array}{l}\text { Projeto Pedagógico do } \\
\text { Curso; } \\
\text { Documentos de fóruns } \\
\text { e eventos; }\end{array}$ & $\begin{array}{l}\text { Informações sobre a EaD na } \\
\text { IES; } \\
\text { Dados sobre a EaD no Brasil. }\end{array}$ & $\begin{array}{lr}\text { A possibilidade } & \text { de } \\
\text { análise local EaD. } & \\
\text { A possibilidade } & \text { de } \\
\text { conhecer sobre } & \text { a } \\
\text { amplitude da EAD. } & \end{array}$ \\
\hline
\end{tabular}

Fonte: Elaborado pelos autores.

A análise foi distribuída da seguinte forma: pré-análise, com seleção dos materiais a serem trabalhados, objetivando lidar com os materiais de maior relevância para a pesquisa; categorização, determinando a evolução histórica da Educação a Distância no Brasil; qualificação, visando relacionar as etapas de institucionalização (inovação, habitualização, objetificação e sedimentação) com os eventos de $\mathrm{EaD}$ e; interpretação, objetivando analisar os conteúdos encontrados com a história delineada e detectar as fases de desenvolvimento da EaD no Brasil, principalmente a partir da literatura relacionada aos conceitos de Tolbert e Zucker (2007) sobre os processos inerentes à institucionalização. Inicialmente foi realizada a pré-análise, elaborada a partir da seleção do material, organização dos documentos analisados e leitura flutuante (DELLAGNELO; SILVA, 2005). Em seguida os materiais foram categorizados conforme mostra o Quadro 1.

A análise foi feita de maneira qualitativa, ou seja, não sendo preponderante a quantidade de vezes que cada elemento aparece nos textos, partindo do princípio de que as unidades de registro refletem importância muito mais pela forma com que são colocadas do que pelo número de vezes em que aparecem. Neste sentido, foram avaliadas principalmente a intensidade e relevância dos eventos em EaD encontrados, na perspectiva de que o "[...] uso de regras de enumeração [quantificação] como a intensidade e direção de determinadas ideias 
[...] utilizadas na análise, consolidam sobremaneira a força de qualquer argumento" (DELLAGNELO; SILVA, 2005 p. 109, inserção nossa).

A interpretação dos resultados da análise foi feita relacionando as informações relevantes dos materiais estudados, preservando o caráter qualitativo descritivo dos textos, recorrendo sempre a citações dos documentos ou de contexto para relacionar com o processo de institucionalização analisado, pois para Amado (2000), as citações não têm somente função de ilustrações. Têm, sobretudo, funções fundamentais como de retórica, analítica e probatória.

\section{RESULTADOS E DISCUSSÕES}

\subsection{DELINEAMENTO HISTÓRICO DA EDUCAÇÃO A DISTÂNCIA}

As diversas publicações e documentos analisados mostram que a $\mathrm{EaD}$ não é uma prática recente. Faria e Salvadori (2010), por exemplo, mencionam que os métodos de ensino utilizados pelas civilizações antigas, como as que difundiram o Cristianismo, já eram modelos desenvolvidos de educação a distância. Contudo, estudos mostraram que as citações que aparecem, repetidamente, em diversos trabalhos, tornam-se consenso principalmente a partir do século XIX. Alves (2011) faz uma boa apresentação dessas principais menções históricas, conforme apresentado no Quadro 2.

Nesta pesquisa utilizou-se a análise descritiva dos dados, valendo-se de técnicas univariadas. Faz-se o uso também da estatística alpha de cronbach buscando validar o instrumento de pesquisa. Subsequentemente, usou-se a análise fatorial exploratória e buscouse em seguida testar as hipóteses definidas no referencial teórico do trabalho através de um modelo de regressão linear.

Quadro 2 Evolução histórica da EaD no mundo

\begin{tabular}{|c|l|}
\hline Ano & \multicolumn{1}{c|}{ Evento } \\
\hline 1728 & $\begin{array}{l}\text { Marco inicial da EaD: é anunciado um curso pela Gazeta de Boston, na edição de 20 de } \\
\text { março, onde o Prof. Caleb Philipps, de Short Hand, oferecia material para ensino e tutoria } \\
\text { por correspondência; }\end{array}$ \\
\hline 1829 & $\begin{array}{l}\text { Na Suécia é inaugurado o Instituto Líber Hermondes, que possibilitou a mais de } 150.000 \\
\text { pessoas realizarem cursos através da EaD; }\end{array}$ \\
\hline 1840 & $\begin{array}{l}\text { Na Faculdade Sir Isaac Pitman, no Reino Unido, é inaugurada a primeira escola por } \\
\text { correspondência na Europa; }\end{array}$ \\
\hline 1856 & $\begin{array}{l}\text { Em Berlim, a Sociedade de Línguas Modernas patrocina os professores Charles Toussaine } \\
\text { e Gustav Laugenschied para ensinarem a Língua francesa por correspondência; }\end{array}$ \\
\hline 1892 & $\begin{array}{l}\text { O Departamento de Extensão da Universidade de Chicago, nos Estados Unidos da } \\
\text { América, é criada a Divisão de Ensino por Correspondência para preparação de docentes; }\end{array}$ \\
\hline 1922 & São iniciados cursos por correspondência na União Soviética; \\
\hline
\end{tabular}




\begin{tabular}{|c|c|}
\hline 1935 & $\begin{array}{l}\text { O Japanese National Public Broadcasting Service inicia seus programas escolares pelo } \\
\text { rádio, como complemento e enriquecimento da escola oficial; }\end{array}$ \\
\hline 1947 & $\begin{array}{l}\text { Inicia-se a transmissão das aulas de quase todas as matérias literárias da Faculdade de } \\
\text { Letras e Ciências Humanas de Paris, França, por meio da Rádio Sorbonne; }\end{array}$ \\
\hline 1948 & Na Noruega, é criada a primeira legislação para escolas por correspondência; \\
\hline 1951 & $\begin{array}{l}\text { Nasce a Universidade de Sudáfrica, atualmente a única universidade a distância da África, } \\
\text { que se dedica exclusivamente a desenvolver cursos nesta modalidade; }\end{array}$ \\
\hline 1956 & $\begin{array}{l}\text { A Chicago TV College, Estados Unidos, inicia a transmissão de programas educativos } \\
\text { pela televisão, cuja influência pode notar-se rapidamente em outras universidades do país, } \\
\text { que não tardaram em criar unidades de EaD baseadas fundamentalmente na televisão; }\end{array}$ \\
\hline 1960 & $\begin{array}{l}\text { Na Argentina, nasce a Tele Escola Primária, do Ministério da Cultura e Educação, que } \\
\text { integrava os materiais impressos à televisão e à tutoria; }\end{array}$ \\
\hline 1968 & $\begin{array}{l}\text { É criada a Universidade do Pacífico Sul, uma universidade que pertence a } 12 \text { países da } \\
\text { Oceania; }\end{array}$ \\
\hline 1969 & No Reino Unido, é criada a Fundação da Universidade Aberta; \\
\hline 1971 & A Universidade Aberta Britânica é fundada; \\
\hline 1972 & Na Espanha, é fundada a Universidade Nacional de Educação a Distância; \\
\hline 1977 & Na Venezuela, é criada a Fundação da Universidade Nacional Aberta; \\
\hline 1978 & Na Costa Rica, é fundada a Universidade Estadual a Distância; \\
\hline 1984 & Na Holanda, é implantada a Universidade Aberta; \\
\hline 1985 & $\begin{array}{l}\text { É criada a Fundação da Associação Europeia das Escolas por Correspondência; } \\
\text { Na Índia, é realizada a implantação da Universidade Nacional Aberta Indira Gandhi; }\end{array}$ \\
\hline 1987 & $\begin{array}{l}\text { É divulgada a resolução do Parlamento Europeu sobre Universidades Abertas na UE; } \\
\text { É criada a Fundação da Associação Europeia de Universidades de Ensino a Distância; }\end{array}$ \\
\hline 1988 & Em Portugal, é criada a Fundação da Universidade Aberta; \\
\hline 1990 & $\begin{array}{l}\text { É implantada a rede Europeia de EaD, baseada na declaração de Budapeste e no relatório } \\
\text { da Comissão sobre educação aberta e a distância na UE. }\end{array}$ \\
\hline
\end{tabular}

Fonte: Baseado em Alves (2011, p. 89-90).

Mais recentemente, inclusive no Brasil, como se discute a seguir, a EaD deixa de ter seu foco centrado na correspondência, como foi marcado pela geração anterior, e passa a ser praticada principalmente pelas novas tecnologias de informação e comunicação (TIC). Em consequência, o desenvolvimento das TIC acrescenta novos potenciais às relações de ensino e aprendizagem e sua prática começa a ser institucionalizada em muitos países, inclusive no Brasil.

\subsection{DESENVOLVIMENTO INSTITUCIONAL DA EAD NO BRASIL}

O Brasil, entre 1900 e 1940, registra as primeiras inserções, de maneira bem esporádica, de várias modalidades de treinamentos ou formações a distância. Em 1904 é registrada a primeira formação por correspondência no Brasil (ALVES, 2011), realizada pelo Jornal do Brasil e voltada especificamente para datilógrafos. A ideia possivelmente foi implantada para atender às demandas do próprio jornal. Do mesmo modo, nas décadas de 1920 e 1930, associada principalmente à figura de Edgard Roquette-Pinto, foi criada a Rádio 
Sociedade do Rio de Janeiro e a Rádio-Escola Municipal no Rio. Essas experiências, em âmbito municipal, foram baseadas principalmente na modalidade por correspondência com o apoio do Rádio.

Nota-se que essas e outras experiências da época tiveram, no contexto brasileiro, um caráter inovador e de pioneirismo. As inserções de novas demandas de mercado e a possibilidade, como foi o caso do rádio, permitia que novas tecnologias começassem a serem usadas para disseminar cursos de diversas áreas para estudantes da mesma ou de outras localidades. Esses casos, ao perdurarem ao longo de mais três décadas, e com a inserção de novas experiências, como foi o caso do Instituto Rádio-Técnico Monitor, que passou a oferecer sistematicamente, no ano de 1939, cursos profissionalizantes por correspondência (ALVES, 2011), fez com que a prática de EaD começasse a ser habitualizada Brasil.

Esse primeiro momento de iniciativas de EaD no Brasil foi relevante na medida em que inseriu algumas forças causais e padrões estáveis de comportamento (ZUCKER, 1977). Esse período, considerando Tolbert e Zucker (2007), foi evidenciado, primeiro, por processos de habitualização, com características de adoção bem homogêneas entre uma experiência e outra, como é o caso da Radio, no Rio, e do Instituto Monitor, em São Paulo. Segundo, com pouca teorização a respeito e com fracassos estruturais, como é o caso da Rádio Sociedade do Rio de Janeiro, pois só na década de 1960 é que "se efetivaram as maiores experiências como esses novos modelos" (FARIA; SALVADORI, 2010, p. 18). E, por último, uma alta variação na implementação dessas experiências, como elencado anteriormente.

Nas décadas de 1940 a 1970, por sua vez, a EaD no Brasil se intensifica ainda mais. Uma característica desse período foi o surgimento de organizações ou movimentos que passaram a durar por períodos de tempo mais longos, algumas persistindo até a atualidade. $\mathrm{Na}$ iniciativa privada, um exemplo é o Instituto Universal Brasileiro, fundado em 1941 e que existe até hoje. Outro é a Universidade do Ar, primeiro praticada de 1941 até 1944, retomando em 1947. Desenvolvida pelo SENAC e SESC, durou somente até 1961, mas deixou disseminada a modalidade de EaD no Sistema S como todo. Para trazer só mais um exemplo da iniciativa privada, dos vários existentes na linha do tempo da evolução da EaD no Brasil (COUTO, 2010), é iniciada, em 1962, em São Paulo, a Occidental School, de origem norte-americana, iniciando com o curso de eletrônica, mas expandindo, na atualidade, para outros cursos como eletricidade, informática, mecânica e refrigeração. 
Essas novas disposições de EaD no Brasil mostram que se inicia um "processo de habitualização que envolve a geração de novos arranjos estruturais em resposta a problemas ou conjuntos de problemas organizacionais específicos (...) de uma dada organização, ou um conjunto de organizações" (TOLBERT; ZUCKER, 2007, p. 204). E as semelhanças desses problemas não se concentram somente na rede privada de ensino. Iniciativas comunitárias e públicas também fazem parte desse processo de pré-institucionalização da EaD no Brasil, como podem ser vistas em iniciativas como a criação das escolas radiofônicas de letramento de jovens e adultos coordenado pela Diocese de Natal, em um Movimento de Educação de Base. E o Instituto Brasileiro de Administração Municipal, existente até hoje, criado em 1952, no Rio de Janeiro e inicia suas atividades na área de educação pública, utilizando-se de metodologia de ensino por correspondência, no ano de 1967.

Desse modo, as iniciativas de segmentos diferentes e que começam a perdurar por longos períodos, faz da $\mathrm{EaD}$ uma modalidade educacional conhecida no Brasil, tanto por suas características estruturais parecidas (SILVA et al., 2011), seja por imitação como foi no caso das experiências radiofônicas ou de várias modalidades de cursos a distância, seja pelos formatos estruturais idiossincráticos, o que evidencia uma relevância desse período para a EaD no Brasil. Contudo, essas iniciativas estavam em grande medida na busca por resolução de problemas parecidos no que tange a alcançar públicos distantes e que demandavam uma formação específica e, ao mesmo tempo, possível de ser ofertada. Como essa é uma característica dos períodos de pré-institucionalização, na medida em que se delineiam formas conjuntas de solução de problemas, a EaD torna-se, pode-se dizer, habitualizada no Brasil.

Entre as décadas de 1970 e 1990, a EaD no Brasil continua incorporando outros aspectos relevantes para seu processo de institucionalização. Essa fase é caracterizada principalmente por uma forte presença dos órgãos públicos e por uma tentativa de estruturar uma EaD formal no País. Esse período pode ser considerado a fase de objetificação do processo de institucionalização da EAD no Brasil, pois a "objetificação envolve o desenvolvimento de um certo grau de consenso social entre os decisores da organização a respeito do valor da estrutura, e a crescente adoção pelas organizações" (TOLBERT; ZUCKER, 2005, p. 205).

A presença pública pode ser notada, pois iniciativas como o Projeto Minerva, em 1970, para educar pessoas adultas via sistemas de rádio brasileiros, já foi elaborado diretamente pelo Ministério da Educação; em 1976 houve a criação do Sistema Nacional de 
Teleducação e; em 1979, a Universidade de Brasília cria cursos veiculados por jornais e revistas, que em 1989 é transformado no Centro de Educação Aberta, Continuada, a Distância (CEAD) e é lançado o Brasil EaD (ALVES, 2011). Os esforços pelos mesmos formatos estruturais se fazem presente nesse período, pois essas iniciativas são corroboradas por outras de mesmas características educacionais, como foi o caso do Instituto Padre Reus e da TV Ceará, em 1994, com cursos voltados para a educação básica; do Centro Internacional de Estudos Regulares, do Colégio Anglo-Americano, fundado em 1981, que também oferecia Ensino Fundamental e Médio a distância e, ainda, o SENAC, em 1883, com cursos profissionais (ALVES, 2011).

Esses exemplos mostram que a EaD no Brasil começa a transitar de um período de iniciativas esporádicas de educação a distância, com os empreendimentos advindos principalmente da iniciativa privada, para compromissos cada vez maiores, com caráter público e universalizado no País. Pode-se dizer que o processo de habitualização identificado nos períodos anteriores começa a dar vez a uma EaD cada vez mais objetificada.

Entre 1990 e 2010, a participação pública na EaD brasileira se torna ainda mais intensa. O Governo Federal, nesse período, faz da EaD uma via formal de capacitação docente, criando em 1992, a UAB. A UAB, além de ser um marco para o início de um projeto para além da objetificação da $\mathrm{EaD}$, sinaliza um processo de sedimentação da educação a distância no País. O quadro 4, a partir das pesquisas de Alves (2011), mostra como essas duas décadas foram relevantes para a institucionalização da EaD no Brasil.

Como visto nesse período, o número de atores envolvidos na $\mathrm{EaD}$ no Brasil sobe consideravelmente. No âmbito federal, o MEC inclui a EaD nas diretrizes e normas gerais que compõem o sistema educacional brasileiro, fazendo-a parte também de suas prerrogativas legais. O Sistema Nacional de Avaliação do Ensino Superior (SINAES) inclui os alunos em $\mathrm{EaD}$ no sistema de avaliação da qualidade da educação superior nacional. No caso de necessidade de mecanismos institucionais para consolidação do desenvolvimento, aprimoramento e consolidação da educação nacional de qualidade, o Conselho Nacional de Educação (CNE) passa a atuar também no âmbito da EaD. Além desses, a EaD hoje vincula também muitos outros atores.

No âmbito Federal, ainda, o Fundo Nacional para o Desenvolvimento da Educação (FNDE) é o responsável pelo repasse financeiro das bolsas de estudo que remuneram secretários, tutores e professores ligados a programas de EaD. A Câmara de Educação 
Superior (CES), que analisa os processos de avaliação preparados pelos avaliadores do Instituto Nacional de Estudos e Pesquisas Educacionais Anísio Teixeira (INEP), realizados para atendimento dos pressupostos do SINAES e encaminhamentos de pareceres para o CNE.

Quadro 3 Processo de Objetificação da EaD no Brasil

\begin{tabular}{|c|c|}
\hline Ano & $\begin{array}{c}\text { Evento } \\
\end{array}$ \\
\hline 1991 & $\begin{array}{l}\text { O programa "Jornal da Educação - Edição do Professor", concebido e produzido pela } \\
\text { Fundação Roquete-Pinto, tem início e, em } 1995 \text { com o nome "Um salto para o Futuro", foi } \\
\text { incorporado à TV Escola (canal educativo da Secretaria de Educação a Distância do } \\
\text { Ministério da Educação) tornando-se um marco na Educação a Distância nacional. }\end{array}$ \\
\hline 1992 & $\begin{array}{l}\text { É criada a Universidade Aberta de Brasília, acontecimento bastante importante na EaD do } \\
\text { país; }\end{array}$ \\
\hline 1995 & $\begin{array}{l}\text { São criados o Centro Nacional de Educação a Distância e o MultiRio, da Secretaria } \\
\text { Municipal de Educação (RJ). Nesse ano também foi criado o Programa TV Escola da } \\
\text { Secretaria de Educação a Distância do MEC; }\end{array}$ \\
\hline 1996 & $\begin{array}{l}\text { É criada a Secretaria de Educação a Distância (SEED-MEC), dentro de uma política que } \\
\text { privilegia a democratização e a qualidade da educação brasileira. Surge também, } \\
\text { oficialmente, a EaD no Brasil, através da LDBEN n }{ }^{\circ} 9.394 \text {, de } 20 \text { de dezembro de } 1996 \text {, } \\
\text { embora somente regulamentada em } 20 \text { de dezembro de } 2005 \text { pelo Decreto } n^{\circ} 5.622 \text { que } \\
\text { revogou os Decretos } n^{\circ} 2.494 \text { de } 10 / 02 / 98 \text {, e } n^{\circ} 2.561 \text { de } 27 / 04 / 98 \text {, com normatização } \\
\text { definida na Portaria Ministerial } n^{\circ} 4.361 \text { de } 2004 \text {; }\end{array}$ \\
\hline 2000 & $\begin{array}{l}\text { É formada a UniRede, Rede de Educação Superior a Distância, consórcio que reúne } \\
\text { atualmente } 70 \text { instituições públicas do Brasil. Nesse ano também nasce o Centro de } \\
\text { Educação a Distância do Estado do Rio de Janeiro (CEDERJ), por intermédio da Secretaria } \\
\text { de Ciência e Tecnologia, as universidades públicas e as prefeituras do Estado do Rio de } \\
\text { Janeiro; }\end{array}$ \\
\hline 2002 & $\begin{array}{l}\text { O CEDERJ é incorporado à Fundação Centro de Ciências de Educação Superior a Distância } \\
\text { do Rio de Janeiro (Fundação CECIERJ); }\end{array}$ \\
\hline 2004 & $\begin{array}{l}\text { Vários programas para a formação inicial e continuada de professores da rede pública, por } \\
\text { meio da EaD, foram implantados pelo MEC, entre eles o Proletramento e o Mídias na } \\
\text { Educação. Estas ações conflagraram na criação do Sistema Universidade Aberta do Brasil; }\end{array}$ \\
\hline 2005 & $\begin{array}{l}\text { É criada a Universidade Aberta do Brasil, uma parceria entre MEC, estados e municípios; } \\
\text { integrando cursos, pesquisas e programas de educação superior a distância; }\end{array}$ \\
\hline 2006 & $\begin{array}{l}\text { Entra em vigor o Decreto }{ }^{\circ} 5.773 \text {, de } 09 \text { de maio de } 2006 \text {, que dispõe sobre o exercício das } \\
\text { funções de regulação, supervisão e avaliação de instituições de educação superior e cursos } \\
\text { superiores de graduação e sequenciais no sistema federal de ensino, incluindo os da } \\
\text { modalidade a distância; }\end{array}$ \\
\hline 2007 & $\begin{array}{l}\text { Entra em vigor o Decreto } n^{\circ} 6.303 \text {, de } 12 \text { de dezembro de 2007, que altera dispositivos do } \\
\text { Decreto } n^{\circ} 5.622 \text { que estabelece as Diretrizes e Bases da Educação Nacional; }\end{array}$ \\
\hline 2008 & $\begin{array}{l}\text { Em São Paulo, uma Lei permite o ensino médio a distância, onde até } 20 \% \text { da carga horária } \\
\text { poderá ser não presencial; }\end{array}$ \\
\hline 2009 & $\begin{array}{l}\text { Entra em vigor a Portaria } \mathrm{n}^{0} 10 \text {, de } 02 \text { julho de } 2009 \text {, que fixa critérios para a dispensa de } \\
\text { avaliação in loco e deu outras providências para a Educação a Distância no Ensino Superior } \\
\text { no Brasil; }\end{array}$ \\
\hline
\end{tabular}

Fonte: Baseado em Alves (2011, p. 89-90).

A UAB é a proponente de todos os projetos de educação superior a distância e, por meio de editais, seleciona IPES que aceitem desenvolver seus programas de educação 
superior a distância nos moldes por ela estabelecidos. E a Coordenação de Aperfeiçoamento de Pessoal de Nível Superior (CAPES), que visa à melhoria da pós-graduação brasileira, por meio de avaliação, divulgação, formação de recursos e promoção da cooperação científica. $\mathrm{Na}$ $\mathrm{EaD}$, a CAPES é a gestora da UAB, inclusive da parte financeira de custeio dos projetos de curso.

As Secretarias Estaduais de Educação (SEE) são responsáveis pelo ensino médio no Brasil e, com relação à $\mathrm{EaD}$, podem firmar convênios para cessão da estrutura física dos polos de apoio presencial. Conduzem projetos de $\mathrm{EaD}$ autônomos, quando dizem respeito ao ensino de jovens e adultos, crianças com necessidades especiais e cursos técnicos. São responsáveis por manter as condições físicas do polo e de criar e manter uma biblioteca que atenda às necessidades dos cursos ali instalados. As Secretarias Municipais de Educação (SME) são responsáveis pelo ensino fundamental no Brasil e, com relação à $\mathrm{EaD}$, podem firmar convênios para cessão da estrutura física dos polos de apoio presencial. Conduzem projetos de $\mathrm{EaD}$ autônomos, quando dizem respeito ao ensino de crianças e à pré-escola. São responsáveis por manter as condições físicas do polo e por criar e manter uma biblioteca que atenda às necessidades dos cursos ali instalados.

No âmbito da avaliação, existe o Instituto Nacional de Estudos e Pesquisas Educacionais Anísio Teixeira (INEP), que realiza as avaliações institucionais, de cursos e de alunos especificadas pelo SINAES, também para alunos também na modalidade a distância. O Exame Nacional de Desempenho dos Estudantes (ENADE), que avalia o conhecimento de alunos também na modalidade a distância. O Exame Nacional do Ensino Médio (ENEM), que realiza as provas de vestibular para seleção dos alunos. E a Comissão Própria de Avaliação (CPA), onde cada IES avalia a qualidade educacional pretendida.

As IPES oferecem cursos técnicos e superiores a distância e disponibilizam seus professores para ministrarem esses cursos. E os Núcleos de Educação a Distância (NED), são instituídos pelas IPES com diversas nomenclaturas e com diversos desenhos estruturais. Tomando por base as exposições realizadas durante o VII ESUD , em dezembro/2010, a imensa maioria das IPES tem organizado suas estruturas de EaD como Núcleos, atrelados à reitoria da universidade. No caso, por exemplo, da Universidade Federal Rural de Pernambuco (UFRPE), e de umas poucas outras instituições, essa estrutura se configura como Unidade Acadêmica ou Centro, ganhando status e estrutura. "Praticamente todos os NEDs são estruturas independentes dos cursos presenciais, mas vale destacar que na Universidade 
Estadual de Londrina, a EaD é distribuída pelos mesmos departamentos dos cursos presenciais" complementa CoordEaD (2012).

E os Polos de Apoio Presencial (PAP), que são elementos importantes para a sustentação das comunidades de aprendizagem e prática existentes hoje no sistema UAB, além de ser um espaço significativo para que tanto o capital social quanto o cultural se desenvolvam. Geralmente se localizam em escolas públicas municipais. Em 2010 existiam 720 PAP.

Nota-se claramente que a EaD passa a ser incorporada, salvo suas bases específicas, como é o caso da participação dos municípios e a criação dos polos em $\mathrm{EaD}$, ao sistema formal de ensino brasileiro. Isso é relevante para sua institucionalização na medida em que o

[...] processo de objetivação envolve o desenvolvimento de um certo consenso social entre os decisores da organização a respeito do valor da estrutura. A objetivação da estrutura é, em parte, conseqüência do monitoramento que a organização faz dos competidores e de esforços para aumentar a sua competitividade relativa. A institucionalização total envolve a sedimentação, um processo que, fundamentalmente, se apóia na continuidade histórica da estrutura e, especialmente, em sua sobrevivência pelas várias gerações de membros da organização (...). A total institucionalização da estrutura depende dos efeitos conjuntos de uma baixa resistência de grupos de oposição e de promoção e de um apoio continuado de grupos de defensores (...) (PINTO; OLIVEIRA, 2002, p. 10).

Considerando o envolvimento dos diversos entes públicos participantes nas últimas décadas da EaD no Brasil, é possível supor uma concordância mínima com seus aspectos estruturais. Isso não permite afirmar, contudo, que se vive, a partir de 2010, uma "continuidade dessa estrutura" (TOLBERT; ZUCKER, 2005), o que implicaria afirmar que a educação a distância no Brasil estaria sedimentada. A Figura 2 mostra como a EaD tem percorrido o caminho de institucionalização no sistema educacional brasileiro. 
Figura 2 Processo de Institucionalização da Educação a Distância no Brasil

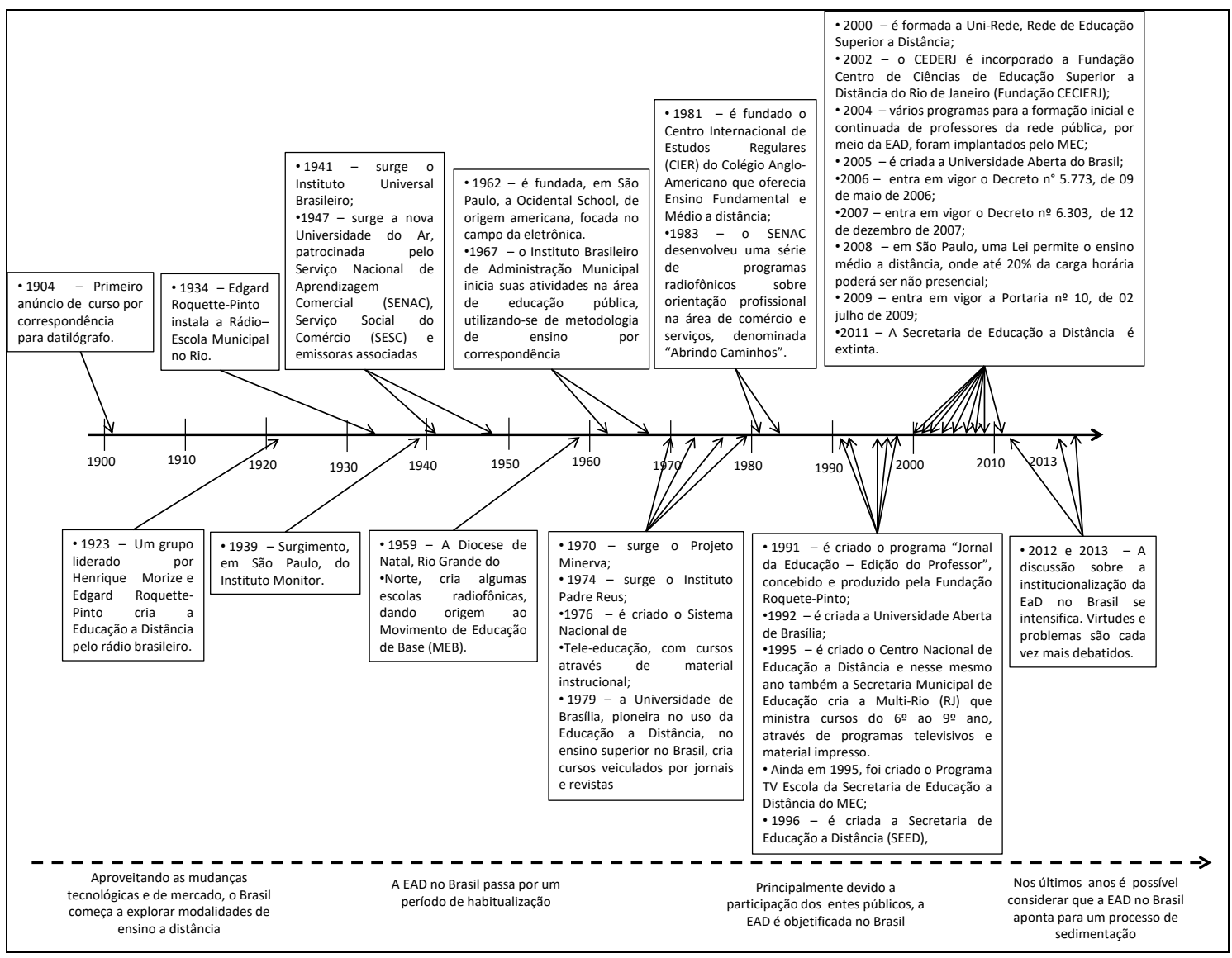

Fonte: Baseado em Alves (2011).

Contudo, a extinção da Secretaria de Educação a Distância (SEED), em 2011, é um fato relevante para o processo de institucionalização da EaD no Brasil. Com a extinção, os projetos da SEED passaram para as Secretarias de Educação Básica ou de Ensino Superior. O MEC considera, a partir dessa data, que a modalidade a distância já se desenvolveu o suficiente para ser incorporada às secretarias de educação formal, não precisando mais ser considerada uma "educação especial" no país. Em uma análise institucional, esse fato é relevante, pois se considerar esse período como sendo já de semi-institucionalização da EaD no Brasil, as variâncias na implementação geralmente são baixas ou, quando muito, moderadas (TOBERT; ZUCKER, 2007). Esse evento, todavia, apresenta uma significativa reviravolta nos aspectos estruturais definidos até então para a EaD. Apesar da alegação do Governo de que com isso sedimenta-se a EaD no Brasil, essa ação pode, por outro lado, trazer efeitos inesperados, corroborando ou não com esse processo. Vale considerar ainda que o próprio processo de institucionalização possui, intrinsecamente, a desinstitucionalização e reinstitucionalização em seu bojo (PINTO; RODRIGUES, 2002). 
Outrossim, os demais trabalhos de temas relacionados não haviam focado especificamente na análise das disciplinas de formação geral, o que indica que há oportunidades para outros estudos no sentido de confirmarem ou não os resultados aqui apresentados, podendo inclusive incluir na análise alunos que estudam em instituições públicas, visto que o presente estudo esteve baseado em alunos de uma instituição privada de ensino.

\subsection{IMPLICAÇÕES DOS PROCESSOS DE INSTITUICIONALIZAÇÃO DA EAD NO BRASIL}

Como visto, essa complexidade de atores e instituições envolvidas resulta num imenso universo com alunos, professores, IPES, governos federal, estadual e municipal, e outras organizações e agentes que fomentam e regulam os cursos nessa modalidade. Como consequência, surgem a formalidade e a previsibilidade advindas do aparato legal que rege a atividade no Brasil. Leis, decretos e portarias estabelecem mecanismos de concessão, avaliação e sanção de instituições, cursos e alunos na modalidade a distância. Isso tem sido relevante para a institucionalização da EaD no Brasil.

Outro fator é o imbricamento entre os diversos níveis federativos, tanto na normalização como na execução das atividades da EaD no Brasil. O Governo Federal institui, autoriza, avalia e financia, mas os governos estaduais e municipais oferecem as instalações físicas e parte do custeio dos projetos (xérox, energia, etc.). As IPES participam cedendo professores e com a gestão dos cursos. Como o número de alunos é sempre grande em cada curso, pois os mesmos estão dispersos geograficamente, o contingente de pessoas envolvido tem se tornado cada vez mais expressivo. "Na EaD da minha universidade temos alunos em quatro Estados brasileiros!" (CoordEaD, 2012). Esse volume, por um lado fortalece a sedimentação, mas por outro dificulta a previsibilidade e a continuidade dos atuais aspectos estruturais que denominam a EaD no Brasil.

Por um lado, conforme destaca o CoordEaD (2012), "um ponto crítico é o modelo de contratação de professores, que são bolsistas contratados por 2 ou 4 meses, o que diminui bastante o comprometimento com qualidade e com objetivos de longo prazo". Dado o volume de contratações por semestre, o processo seletivo é aligeirado e muitas vezes só se conhece o perfil do professor quando o mesmo já está atuando, não sendo raros os desligamentos ainda durante o primeiro período de trabalho do mesmo. Além desses profissionais bolsistas, também existe toda uma logística para a realização das aulas nos polos que requer, além das 
diárias, a viabilização de viagens com carro alugado, ônibus ou avião, em praticamente $70 \%$ dos finais de semana durante o período letivo (CoordEaD, 2012 e 2014). Essa forma de contratação e logística continua a mesma até 2014, por todo o Brasil (CoordEaD, 2014), enfraquecendo a sedimentação da $\mathrm{EaD}$ no Brasil e, por via de conseqüência, seu reconhecimento.

Por outro lado, a cada ano a EaD cresce em números absolutos. Segundo o Censo de 2011 (CENSO EAD.BR, 2011), o Brasil já possuía 3,5 milhões de estudantes em modalidades a distância. Destes, quase 800 mil alunos estavam matriculados em cursos autorizados. Somente a UAB, em 2011, já possuía 587 polos instalados nos municípios brasileiros, distribuídos em 943 cursos de 92 IPES, totalizando mais de 200 mil matrículas (FÓRUM DE ADMINISTRAÇÃO PÚBLICA, 2010).

Uma única IES, como é o caso da UFRPE, demanda um volume considerável de livros produzidos e distribuídos aos alunos todos os semestres (CoordEaD, 2012). Em 2012 já existiam 9 cursos de graduação na UFRPE, com cerca de 7.000 alunos ao todo, matriculados em cerca de 6 disciplinas por semestre, o que demanda a impressão de cerca de 378.000 exemplares. Isso demanda um grande número de pessoas experientes na produção dos livros didáticos com a linguagem dialogada, necessária para esse público, o que envolve tanto os professores autores como os ilustradores (designers gráficos), e arte finalizadores, todos os semestres.

Outro ponto que fortaleceu a institucionalização da EaD pelas IPES brasileiras foi a utilização do processo seletivo ENEM-SISU, no qual o vestibulando pode selecionar a universidade, o curso e o polo desejados da mesma forma que no sistema presencial. Contudo, uma característica a se destacar é que o processo de matrícula nos cursos a distância só se dar após a conclusão das matrículas nos cursos presenciais, “apontando uma nítida preferência pelos cursos presenciais" (CoordEaD, 2014).

A demanda pela EaD no Brasil tem sido, sem dúvida, relevante para o seu processo de institucionalização. Todavia, como o surgimento e o crescimento dos NED foram vertiginosos, muitas IPES e o sistema como um todo, ainda sofrem para se estruturar. A maior parte das universidades ainda tem pouquíssimos professores dedicados a essa modalidade e ainda menos técnicos administrativos à disposição desses núcleos, acarretando uma qualidade aquém da desejada nos serviços prestados. A maior parte desse contingente de pessoas da retaguarda é formada por bolsistas temporários. Além desses problemas com pessoal, muitos 
NEDs "carecem de uma melhor estrutura tecnológica para apoiar suas atividades, inclusive de webconferência, que fica a desejar na maioria dos polos" (CoordEaD, 2014).

Com isso, é possível concluir que a $\mathrm{EaD}$ no Brasil, como todo processo de institucionalização, é uma dinâmica contínua e permanente, sendo a Teoria Institucional um campo teórico relevante para descrever as transformações que ocorrem em áreas estratégicas para o País, como é o caso da EaD. Os problemas discutidos na evolução da EaD brasileira, ao mesmo tempo em que sinalizam para dificultar a sedimentação da modalidade, por outro delineiam características que se tornam identitárias para sua institucionalização.

\section{CONSIDERAÇÕES FINAIS}

O Brasil vem, principalmente a partir do início do século XX, por meio dos avanços tecnológicos, explorando a educação a distância. As iniciativas privadas e a entrada das Universidades Públicas nessa modalidade de ensino entre as décadas de 1950 e 1970 tornou a EaD habitualizada no País. A partir daí, por meio de sua oficialização pelos órgãos públicos, ela se tornou cada vez mais objetificada, sendo nos últimos anos discutida já no âmbito de sua sedimentação, tornando seu processo de institucionalização cada vez mais evidente.

Esse trabalho, de modo geral, ao cooperar com as análises que vem sendo feitas sobre a evolução da EaD no Brasil, considerando seus processos de institucionalização, reforçou os argumentos que vem sendo feitos sobre a sedimentação dessa modalidade de ensino no País. Por um lado, o trabalho corroborou a constatação de que a EaD no Brasil é uma política educacional em expansão, atendendo demandas essenciais e universalizando a educação. Por outro, reforça também as deficiências e dificuldades específicas dessa modalidade de ensino, apontando para uma institucionalização deficitária em termos de qualidade.

Como principais restrições desse estudo podem ser identificadas o pouco aprofundamento sobre como as IPES estão estruturando seus NED e como está sendo o relacionamento desses núcleos com os demais departamentos universitários. Também não foram considerados os relacionamentos intracursos, como é o caso dos Coordenadores de Curso e Coordenadores de Tutoria com os demais professores envolvidos e as Universidades, como um todo.

Como proposta para estudos futuros, pode-se indicar uma pesquisa que analise como cada IPES está implementando sua estrutura de NED e se esses modelos vêm sendo isomorficamente copiados pelas demais instituições, como é o caso do trabalho que acaba de 
analisar o processo de institucionalização do Curso de Administração Pública a Distância da Universidade Federal de Lavras . Esse olhar para dentro pode mostrar mais claramente como está a sedimentação no processo de institucionalização da EaD no Brasil.

\section{REFERÊNCIAS}

ALVES, L. Educação a distância: conceitos e história no Brasil e no mundo. RBAAD: Associação Brasileira de Educação à Distância. v. 10, 2011. p. 83-92.

AMADO, J. S. A técnica de análise de conteúdo. Revista Referência, n. 5. 2000.

BARDIN, L. Análise de conteúdo. (3. Ed). Lisboa: Edições 70. 2004.

CENSO EAD.BR. Relatório analítico da aprendizagem a distância no Brasil 2011. São Paulo: Pearson Education do Brasil.

COSTA, C. J. Palestra durante o Fórum da Área de Administração Pública do Sistema UAB. Comunicação oral. 2010.

CHURCHILL, G. Marketing Research. (7. ed.) Orlando: The Dryden Press. 1999.

COUTO. R. M. L. S. Evolução da EaD no Brasil e no mundo. Xtimeline. 2010. Disponível em: http://www.xtimeline.com/timeline/Linha-Do-Tempo-Da-EAD-No-Brasil-E-No-Mundo. Acesso em: 26 abr. 2013.

DEC. (5.622/05). Ministério da Educação. Disponível em:

http://portal.mec.gov.br/seed/arquivos/pdf/dec_5622.pdf. Acesso em: 01 jan. 2011.

DELlaGNELO, E. H. L.; SILVA, R. C. Análise de conteúdo e sua aplicação em pesquisa na administração. In: VIEIRA, M. M. F.; ZOUAIN, D. M. (Orgs). Pesquisa qualitativa em administração: teoria e prática. Rio de Janeiro: FGV. p. 97-110. 2005.

FACHIN, R. C.; MENDONÇA, J. R. C. Selznick: uma visão da vida e da obra dos percursos da perspectiva institucional na teoria organizacional. In: VIEIRA, M. M. F.; CARVALHO, C. A. (Orgs.). Organizações, instituições e poder no Brasil. Rio de Janeiro, FGV Editora. 2003.

FARIA, A. A.; SALVADORI, A. A educação a distância e seu movimento histórico no Brasil. Revista das Faculdades Santa Cruz, v. 8, n. 1., p. 15-22. 2010.

FERRUGINI, L.; SOUZA, D. L.; SIQUEIRA, M.; CASTRO, C. C. Educação a distância como política de inclusão: um estudo exploratório nos polos do sistema Universidade Aberta do Brasil em Minas Gerais. Revista GUAL. Florianópolis, v. 6, n. 2, p. 1-21, abr. 2013.

HAGUETTE, T. M. F. Metodologias qualitativas na sociologia. Petrópolis: Vozes. 1987. 
HATCH, M. J.; CUNLIFFE, A. Organization theory: modern, symbolic and postmodern perspectives. New York: Oxford University Press. 2006.

LDBEN. Ministério da Educação. Disponível em:

http://portal.mec.gov.br/arquivos/pdf/ldb.pdf Acesso em: 01 jan. 2011.

MEC. Ministério da Educação. Disponível em:

http://portal.mec.gov.br/index.php?option=com_content\&view=article\&id=289\&Itemid=356 Acesso em: 31 dez. 2010.

MEYER, J.; ROWAN, B. Institutionalized organizations: formal structure as myth and ceremony. American Journal of Sociology, v. 83, n. 2, p. 340-63. 1977.

MOORE, M. G. Toward a theory of independent learning and teaching. Journal of Higher Education, v. 44, p. 661-679. 1973.

MORAES, R. C. Educação a distância e ensino superior: introdução didática a um tema polêmico. São Paulo: Senac, 2010.

MORAN, J. M. Novos caminhos do ensino a distância. Informe CEAD. SENAI, Rio de Janeiro, v. 1, n. 5, p. 1-3. Disponível em: http://www.eca.usp.br/prof/moran/dist.htm. Acesso em: 01 jan. 2011. 1994.

NEVADO, R. A. Processos interativos e a construção de conhecimento por estudantes de licenciatura em contexto telemático. Porto Alegre: Ed. UFRGS. p. 148-164. 1996.

NUNES, I. B. Noções de Educação a Distância. Disponível em:

http://www.diaadiaeducacao.pr.gov.br. Acesso em: 31 dez. 2010. 1994.

OPEN UNIVERSITY. Disponível em: http://www.open.ac.uk/. Acesso em: 02 jan. 2011. 2007.

PINTO, M. S. L.; RODRIGUES, R. R. Análise do momento crítico do setor elétrico brasileiro e suas variações institucionais. In: ENANPAD, 26, 2002, Salvador-BA. Anais. Disponível em:

http://www.anpad.org.br/diversos/trabalhos/EnANPAD/enanpad_2002/POP/POP549.pdf. Acesso em: 26 abr. 2013.

RODRIGUES, C. M. C.; NUNES, R. S.; BEUREN, G. M.; MIORANDO, B. S. Avaliação de Cursos de Graduação na Modalidade a Distância: uma Experiência no Curso de Graduação em Administração da Universidade Federal de Santa Catarina. Revista GUAL. Florianópolis, v. 7, n. 1, p. 191-212, jan. 2014.

SCOTT, W. R. Institutional theory. Encyclopedia of Social Theory. George Ritzer (Ed.). Thousand Oaks-CA: Sage. 2004. 
SEGENREICH, S. C. D. Os múltiplos caminhos e descaminhos da institucionalização da EaD na educação superior brasileira. In: ESUD, 7, Cuiabá-MT. Anais... Cuiabá-MT, VII ESUD. 2010.

SELZNICK, P. TVA and the grass roots. New York: Ed. Harper and Row. 1966.

SILVA, A. R. L.; NUNES, C. S.; SPANHOL, F. J.; SANTOS, J. V. V.; REBELO, S.

Modelos utilizados pela educação a distância. Revista GUAL. Florianópolis, v. 4, n. 3, p. 153-169, set/dez 2011.

SOUZA, D. L.; FERRUGINI, L.; CASTRO, C. C. O campo de estudos sobre educação a distância: um estudo bibliométrico em periódicos nacionais. Revista GUAL.

Florianópolis, v. 7, n. 3, p. 138-159, set. 2014.

STAKE, R. E. Case Studies. In: DENZIN, N. K.; LINCOLN, Y. S. Handbook of Qualitative Research. California: SAGE Publications. p. 237-247. 1994.

TOLBERT, P. M.; ZUCKER, L. G. A Institucionalização da Teoria Institucional. In: CLEGG, S.; HARDY, C.; NORDY, W. Handbook de Estudos Organizacionais. São Paulo: Atlas. p. 196-217. 2007.

WILLIS, B. (1994). Distance education: strategies and tools. New Jersey: Education Technology Publications.

ZUCKER, L. G. The role of institutionalization in cultural persistence. American Sociological Review, v. 42, n. 5. p. 726-743. 1977. 